\title{
Vulvar cancer: epidemiology, clinical presentation, and management options
}

\author{
This article was published in the following Dove Press journal: \\ International Journal of Women's Health \\ 20 March 2015 \\ Number of times this article has been viewed
}

\author{
Ibrahim Alkatout' \\ Melanie Schubert' \\ Nele Garbrecht ${ }^{2}$ \\ Marion Tina Weigel' \\ Walter Jonat' \\ Christoph Mundhenke' \\ Veronika Günther' \\ 'Department of Gynecology and \\ Obstetrics, ${ }^{2}$ Institute for Pathology, \\ University Hospitals Schleswig- \\ Holstein, Campus Kiel, Kiel, Germany
}

Epidemiology: Vulvar cancer can be classified into two groups according to predisposing factors: the first type correlates with a HPV infection and occurs mostly in younger patients. The second group is not HPV associated and occurs often in elderly women without neoplastic epithelial disorders.

Histology: Squamous cell carcinoma (SCC) is the most common malignant tumor of the vulva (95\%).

Clinical features: Pruritus is the most common and long-lasting reported symptom of vulvar cancer, followed by vulvar bleeding, discharge, dysuria, and pain.

Therapy: The gold standard for even a small invasive carcinoma of the vulva was historically radical vulvectomy with removal of the tumor with a wide margin followed by an en bloc resection of the inguinal and often the pelvic lymph nodes. Currently, a more individualized and less radical treatment is suggested: a radical wide local excision is possible in the case of localized lesions (T1). A sentinel lymph node (SLN) biopsy may be performed to reduce wound complications and lymphedema.

Prognosis: The survival of patients with vulvar cancer is good when convenient therapy is arranged quickly after initial diagnosis. Inguinal and/or femoral node involvement is the most significant prognostic factor for survival.

Keywords: vulvar cancer, HPV infection, radical vulvectomy, groin dissection, sentinel lymph node biopsy, overall survival

\section{Introduction}

Vulvar cancer is the fourth most common gynecologic cancer and contains $5 \%$ of all malignancies of the female genital tract (after cancer of the uterine corpus, ovary, and cervix). ${ }^{1,2}$ There are several histological types, whereas squamous cell carcinoma of the vulva is the most common category (95\%), followed by melanoma, sarcoma, and basalioma. ${ }^{3}$ The survival rate and the relapse-free time correlate with specific histologic growth patterns, as explained below. The prognosis is good if vulvar cancer is diagnosed at an early stage. The correct treatment option for vulvar cancer is important because of its strong influence on sexuality. In recent years, a lot of changes have been made concerning the treatment of vulvar cancer: more conservative, less radical, and more individualized surgery followed by enhanced psychosexual outcomes. Regular prevention followed by early detection and histological examination of any suspicious vulvar lesions help to detect vulvar cancer in the early stages and reduce consecutively morbidity and mortality.

\section{Vulvar anatomy}

The vulva is comprised of the female external genitalia, which include the labia majora and minora, clitoris, vestibule, vaginal introitus, and urethral meatus. The vulva serves 
to direct urine flow, prevent foreign bodies from entering the urogenital tract, as well as being a sensory organ for sexual arousal. The internal pudendal artery and, to a lesser extent, the external pudendal artery are responsible for the blood supply. The ilioinguinal and genitofemoral nerve innervates the anterior part of the vulva, whereas the posterior part is innervated by the perineal branch of the posterior cutaneous nerve. The majority of the vulva is drained by lymphatics that pass laterally to the superficial inguinal lymph nodes. The clitoris and anterior labia minora may also drain directly to the deep inguinal or internal iliac lymph nodes (Figure 1). ${ }^{4}$

\section{Epidemiology}

Vulvar cancer can be distinguished into two separate diseases: the first type involves a human papillomavirus (HPV) infection that causes vulvar intraepithelial neoplasia (VIN), a predisposing factor for vulvar cancer. Early studies analyzed tissue samples from 48 patients with vulvar cancer. HPV DNA was identified by polymerase chain reaction (PCR) in $48 \%$ of explored cases, of which $96 \%$ were from subtypes 16 and $18 .{ }^{5,6}$ An estimated $80 \%$ of untreated women suffering from VIN III develop invasive vulvar cancer. ${ }^{7}$ This kind of vulvar cancer mentioned above often occurs in younger patients (35-65 years of age), and a recent review pointed out that approximately $15 \%$ of all vulvar cancers develop in women under age $40 .{ }^{8}$ Other predisposing factors, eg, condylomata or sexually transmitted diseases (STD) in the past, low economic status, or nicotine abuse, have also been found. ${ }^{9}$

The second type of vulvar cancer includes vulvar nonneoplastic epithelial disorders (VNED) and advanced age that lead to cellular atypia and eventually to cancer. ${ }^{10}$ Elderly patients (55-85 years), in particular, show a low rate of HPV infections and consequently seldom any association with cervical neoplasia. Diabetes mellitus, hypertension, and obesity seem to correlate with the incidence of vulvar cancer, but do not appear to be responsible. ${ }^{11}$ Lichen sclerosus, a subgroup of VNED, is mooted as a predisposing risk factor in the development of HPV-negative vulvar cancer. Because of a severe pruritus caused by the lichen, the "itchscratch cycle" leads to a squamous cell hyperplasia ${ }^{12}$ and over time a progression to atypia, followed by VIN and eventual invasive cancer. ${ }^{13,14}$

\section{Clinical features}

The most commonly described symptom of vulvar cancer is a long history of pruritus. Less frequently reported symptoms include vulvar bleeding, dysuria, discharge, and pain.

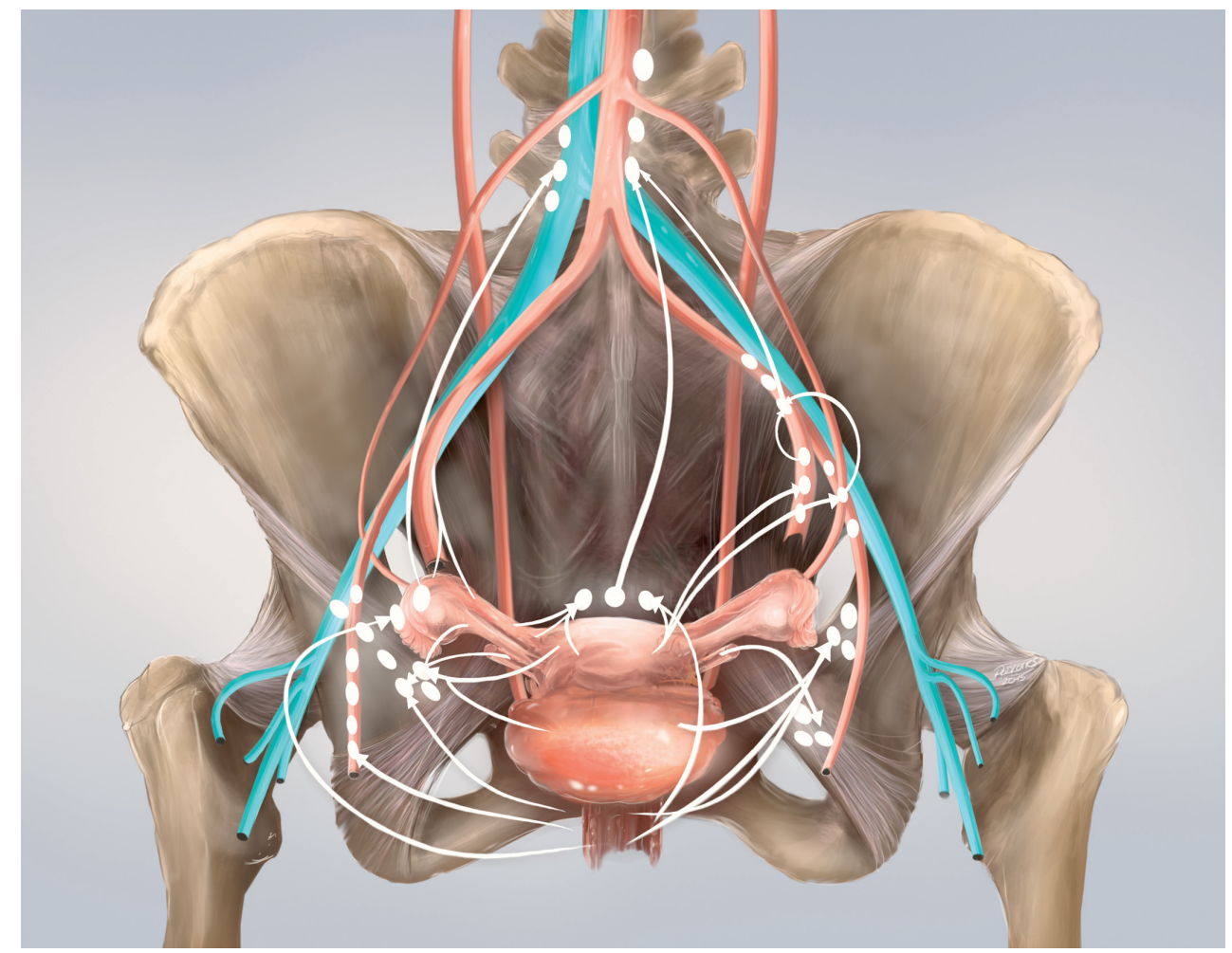

Figure I Lymphatic drainage of the vulva. 
The most obvious manifestation of vulvar cancer is a vulvar lump or mass, which may present ulcerated, leukoplakic, fleshy, or warty. ${ }^{2}$

\section{Histology}

Squamous cell carcinoma (SCC) accounts for approximately $95 \%$ of malignant tumors of the vulva ${ }^{15}$ and can be grouped into three main histological subtypes of vulvar SCC: warty, basaloid, and keratinizing. The predominant type, keratinizing, accounts for $65 \%-80 \%$ of vulvar SCCs; the basaloid and warty types of SCC account for the remaining 20\%-35\%. ${ }^{16}$ The keratinizing type usually occurs in postmenopausal women; the warty/ basaloid types tend to occur more often in premenopausal or perimenopausal women. The keratinizing type is usually formed by well or moderately differentiated cells with an absence of koilocytosis. ${ }^{17}$ Figures $2-4$ show the histology of a keratinizing SCC and the transition to normal vulvar epithelia. Even with immunohistological staining, the secure differentiation between tumors already invading the stroma for more than $1.0 \mathrm{~mm}$ and those invading less than $1.0 \mathrm{~mm}$ is not possible.

The warty or basaloid types of SCC are often associated with a VIN. The basaloid type typically grows in bands, sheets, or nests within a desmoplastic stroma, and focal cytoplasmic maturation and keratinization may be observed. The warty type exhibits invasion as bulbous or irregular jagged nests, often with prominent keratinization. ${ }^{18}$

Vulvar melanoma is the second most common neoplasm of the vulva. The majority of lesions involve the clitoris or labia minora. Any pigmented lesion on the vulva should be excised for diagnosis unless it has been known and unchanged for many years. ${ }^{19}$ Other histological subtypes include verrucous carcinoma, basal cell carcinoma, giant cell carcinoma, acantholytic SCC, Bartholin's gland cancer, and Paget's disease. ${ }^{20,21}$

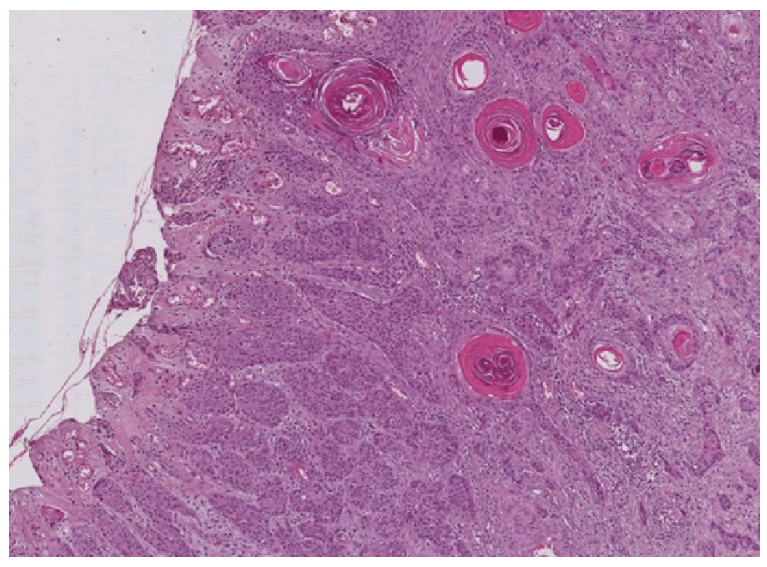

Figure 2 Keratinizing squamous cell carcinoma of the vulva (Hematoxylin and eosin stain, $\times 5)$.

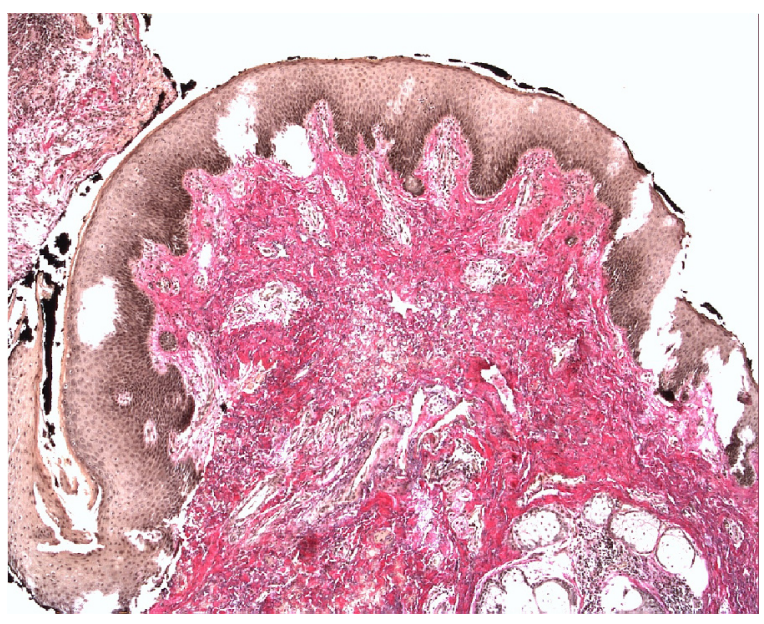

Figure 3 Elastica van Giesson stained (5× magnification) PTIG2 vulvar carcinoma.

\section{Staging}

Vulvar cancer is staged using the American Joint Committee on Cancer TNM staging system and the International Federation of Gynecology and Obstetrics (FIGO) staging systems (Table 1). ${ }^{22}$ These two systems are very similar; both classify vulvar cancer on the basis of three factors: the size of the tumor $(\mathrm{T})$, whether the cancer has spread to lymph nodes $(\mathrm{N})$, and whether it has spread to distant sites (M). The staging system for vulvar cancer is built on surgical data since 1988. The final diagnosis is dependent upon thorough histopathologic evaluation of the operative specimen (vulva and lymph nodes). Various modifications have been made over the years, with a subdivision of stage I added in 1994. The FIGO staging was last reviewed in 2009 by the FIGO Committee on Gynecologic Oncology, 22 to give better prognostic distinction between the particular stages and to guide the clinical treatment more exactly.

Staging reflects the characteristics of vulvar cancer growth that develops in the following way: first, by direct

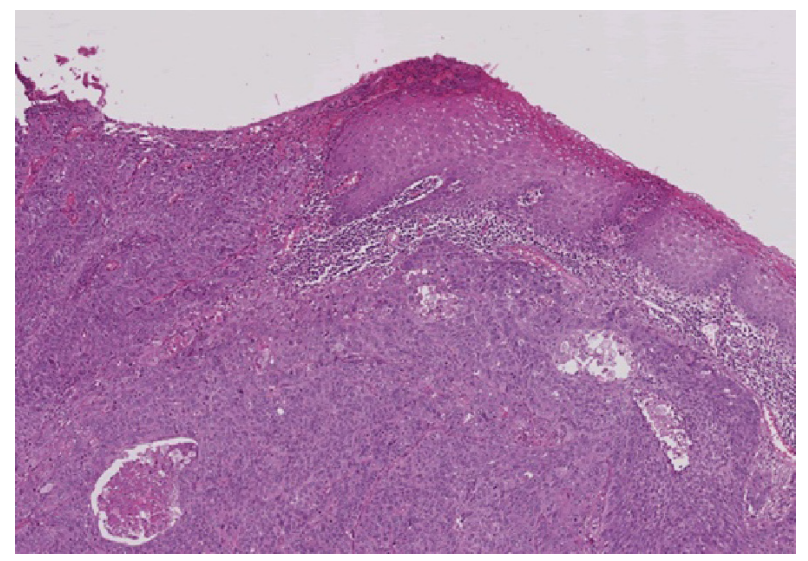

Figure 4 Transition from normal epithelia to squamous cell carcinoma of the vulva (Hematoxylin and eosin stain, $\times 5$ ). 
Table I Staging vulvar cancer (TNM and International Federation of Gynecology and Obstetrics, FIGO)

\begin{tabular}{|c|c|c|c|}
\hline \multicolumn{4}{|c|}{ Primary tumor $(\mathrm{T})$} \\
\hline TNM categories & FIGO stages & Definition & Surgery \\
\hline $\mathrm{TX}$ & & Primary tumor cannot be assessed & \\
\hline T0 & & No evidence of primary tumor & \\
\hline Tis & & Carcinoma in situ & \\
\hline Tla & IA & $\begin{array}{l}\text { Lesions } 2 \mathrm{~cm} \text { or less in size, confined to the vulva or perineum and } \\
\text { with stromal invasion } 1.0 \mathrm{~mm} \text { or less }\end{array}$ & WLE, no LNE \\
\hline TIb & IB & $\begin{array}{l}\text { Lesions more than } 2 \mathrm{~cm} \text { size or any size with stromal invasion more } \\
\text { than } 1.0 \mathrm{~mm} \text {, confined to the vulva or perineum }\end{array}$ & WLE, LNE ipsilateral \\
\hline $\mathrm{T} 2$ & II & $\begin{array}{l}\text { Tumor of any size with extension to adjacent perineal structures } \\
\text { (lower/distal I/3 urethra, lower/distal I/3 vagina, anal involvement) }\end{array}$ & $\begin{array}{l}\text { Modified radical vulvectomy } \\
\text { (hemivulvectomy, anterior or } \\
\text { posterior vulvectomy), LNE bilatera }\end{array}$ \\
\hline T3 & IVA & $\begin{array}{l}\text { Tumor of any size with extension to any of the following: upper/ } \\
\text { proximal } 2 / 3 \text { urethra, upper/proximal } 2 / 3 \text { vagina, bladder mucosa, } \\
\text { rectal mucosa or fixed to pelvic bone }\end{array}$ & $\begin{array}{l}\text { Neoadjuvant chemoradiation } \\
\text { and selected surgery, no LNE }\end{array}$ \\
\hline \multicolumn{4}{|c|}{ Regional lymph nodes (N) } \\
\hline NX & & Regional lymph nodes cannot be assessed & \\
\hline No & & No regional lymph node metastasis & \\
\hline $\mathrm{NI}$ & & One or two regional lymph nodes with the following features & \\
\hline $\mathrm{Nla}$ & IIIA & One or two node metastases, each $5 \mathrm{~mm}$ or less & \\
\hline NIb & IIIA & One lymph node metastasis $5 \mathrm{~mm}$ or greater & \\
\hline N2 & IIIB & Regional lymph node metastasis with the following features & \\
\hline $\mathrm{N} 2 \mathrm{a}$ & IIIB & Three or more lymph node metastases each less than $5 \mathrm{~mm}$ & \\
\hline $\mathrm{N} 2 \mathrm{~b}$ & IIIB & Two or more lymph node metastases $5 \mathrm{~mm}$ or greater & \\
\hline $\mathrm{N} 2 \mathrm{c}$ & IIIC & Lymph node metastasis with extracapsular spread & \\
\hline N3 & IVA & Fixed or ulcerated regional lymph node metastasis & \\
\hline \multicolumn{4}{|c|}{ Distant metastasis (M) } \\
\hline M0 & & No distant metastasis & \\
\hline MI & IVB & Distant metastasis (including pelvic lymph node metastasis) & \\
\hline
\end{tabular}

Abbreviations: WLE, wide local excision; LNE, lymphonodectomy; FIGO, International Federation of Gynecology and Obstetrics.

expansion into the contiguous organs (the vagina, urethra, and anus), followed by lymphatic metastasis to regional lymph nodes (from the inguinal to the femoral to the pelvic lymph nodes), and finally by hematogenous spread to distant sites (liver, lungs, and bones). ${ }^{7}$ The risk of nodal metastasis increases with the stage of disease, the size of lesion, and the depth of invasion, ${ }^{8,23}$ and these are the most important prognostic factors for vulvar cancer. ${ }^{24-26}$

There is no role for diagnostic imaging in the primary detection and characterization of vulvar cancer. However, imaging (MR) may play a role in evaluation of the local extent of disease in advanced cases, especially if urethral invasion is suspected, as well as in the evaluation of lymphadenopathy (US, CT, MRI) and distant metastatic disease (CT and PET CT). ${ }^{27}$ Using the ultrasound, vulvar cancer appears as a soft tissue mass with internal vascularity. On CT, vulvar cancer appears as a nonspecific soft tissue mass, and on MRI, the tumor shows intermediate signal intensity on T1W and high signal intensity on $\mathrm{T} 2 \mathrm{~W}$ sequences.

\section{Treatment}

\section{Surgical therapy}

Historically, the gold standard for even a small invasive carcinoma of the vulva was radical vulvectomy with removal of the primary tumor with a wide margin followed by an en bloc resection of the inguinal and, frequently, the pelvic lymph nodes. ${ }^{4}$ This operation showed a high morbidity rate with approximately $50 \%$ of wound infections and postoperative complications. The extensive nature of the operation and the inevitable distortion of the appearance of the perineal area can lead to major problems for the patient concerning relationship, sexual function, and, consequently, body image and self-assurance. ${ }^{28}$ Accordingly, in most large centers, the traditional en bloc resection has been replaced by the so-called triple incision. Besides the vulvectomy dissection-shape incision, two separate incisions in the groin area are made for inguinal LNE. This procedure shows a markedly lower rate of wound-healing disorders. ${ }^{29}$ 


\section{Management of the primary lesion}

In order to avoid psychosexual morbidity, a radical wide local excision is possible in the case of localized lesions. $\mathrm{T} 1$ lesions with no extension to adjacent perineal structures (ie, urethra, vagina, and/or anus) might be treated by wide local excision. This operation is as effective as radical vulvectomy in preventing local recurrence. ${ }^{30-32}$ Table 1 shows the tumor size and the recommended operative procedure.

Radical vulvectomy implies removal of the entire vulva down to the level of the deep fascia of the thigh, the periosteum of the pubis, and the inferior fascia of the urogenital diaphragm. A tumor-free margin $\geq 1 \mathrm{~cm}$ is required since a smaller margin is associated with an increased local recurrence risk. This was shown in a retrospective series of 135 patients that found a lower rate of local recurrence in cases with a normal tissue margin of $\geq 1 \mathrm{~cm}$ compared $<8 \mathrm{~mm}(0 \%$ versus $50 \%){ }^{31}$ Radical vulvectomy is often performed in connection with either a unilateral or a bilateral groin node dissection. In some cases, a modified radical vulvectomy (including hemivulvectomy) can be performed, which means that only the anterior, posterior, left, or right part of the vulva is removed. T2 lesions with extension to adjacent perineal structures should be treated by radical vulvectomy or hemivulvectomy, as mentioned above. The important oncologic principle remains the same: adequate excision margins to all sides and deep to the tumor.

If the tumor involves the urethra, the distal $1 \mathrm{~cm}$ can be excised without affecting continence. Otherwise, if more than the distal $1 \mathrm{~cm}$ of the urethra must be excised, the patient will require an additional procedure to prevent urinary incontinence. In some cases, this might be an anterior exenteration with formation of a neobladder.

For patients with a tumor at or close to the surgical margins $(\leq 8 \mathrm{~mm})$, a re-excision is suggested, or at least an adjuvant radiation therapy for those who do not want to undergo another surgical procedure. . $^{33,34}$

In some cases of extensive vulvar cancer, plastic surgery is recommended for covering the defect. The multidisciplinary team working with plastic surgery colleagues enhances the spectrum of available operative therapy using local fasciocutaneous skin-flaps (eg, medial-thigh flap, pudendal-thigh flap, or inferior-gluteal flap) for minor cosmetic defects. In cases of more severe wounds extending over larger areas of the vulva and its surrounding regions, regional myocutaneous skin-flaps (eg, rectus abdominis myocutaneous [RAM] flap, gracilis myocutaneous [GMC] flap, or tensor fascia lata [TFL] flap) lead to good results. ${ }^{35}$ Patients receiving a reconstruction after radical vulvectomy show a lower rate of wound dehiscences, vaginal introital stenosis, sexual dysfunction, and urinary problems, compared with those having radical vulvectomy without reconstruction. ${ }^{36}$

\section{Management of lymph nodes}

Inguinofemoral lymphadenectomy is the standard approach for evaluation of the lymph nodes in women with vulvar cancer. An inguinal node dissection alone is associated with a higher incidence of groin recurrence. ${ }^{37}$ Historically, pelvic lymph nodes were also removed, but with an incidence of $2 \%$, pelvic lymph node metastases are quite rare in the early stages of vulvar cancer (T1/T2). ${ }^{38}$ Consequently, pelvic lymphadenectomy is recommended only in the following cases: 3 or more positive unilateral groin lymph nodes, capsule rupture, or macrometastasis $>10 \mathrm{~mm}$. Groin node dissection is performed to assess nodes for evidence of metastasis, which may indicate the need for further therapy and to help reduce the chance of recurrence of further metastasis. The groin nodes are the most important prognostic indicator in SCC of the vulva. ${ }^{26,39}$

The indication for lymphadenectomy depends on the stromal invasion. Infiltration of $<1 \mathrm{~mm}$ is not associated with inguinal node metastases, whereas a tumor thickness $>1 \mathrm{~mm}$ should be treated using at least an ipsilateral inguinofemoral lymphadenectomy or a sentinel lymph node biopsy in the case of inconspicuous groins. ${ }^{30}$ Bilateral groin node dissection should be performed for midline tumors and for those involving the anterior labia minora ${ }^{40,41}$ Large lateral tumors should probably also have bilateral dissection, and definitely if the ipsilateral nodes are positive. ${ }^{41}$ Figure 5 shows the treatment of groin nodes.

Sentinel lymph node (SLN) biopsy is still a new, not yet standardly used treatment, investigating the first potentially metastasized lymph node. SLN biopsy is recommended in those patients who have early stages of vulvar cancer to avoid the operative morbidity that is caused by inguinofemoral lymphadenectomy, such as wound complications or lymphedema. ${ }^{42}$ SLN biopsy may be used in early tumor stage (I or II) and if there are unsuspicious inguinal-femoral lymph nodes clinically and sonographically. ${ }^{43}$ SLN mapping was originally used to identify regional lymph node metastases in breast cancer and cutaneous melanoma and has now been established in patients with early stage vulvar cancer. ${ }^{44,45}$ The SLN can be detected using injected radio colloid $99 \mathrm{mTc}$ (technetium) and isosulfan or methylene blue, which are inserted around the lesion before operation. ${ }^{46} \mathrm{~A}$ handheld 


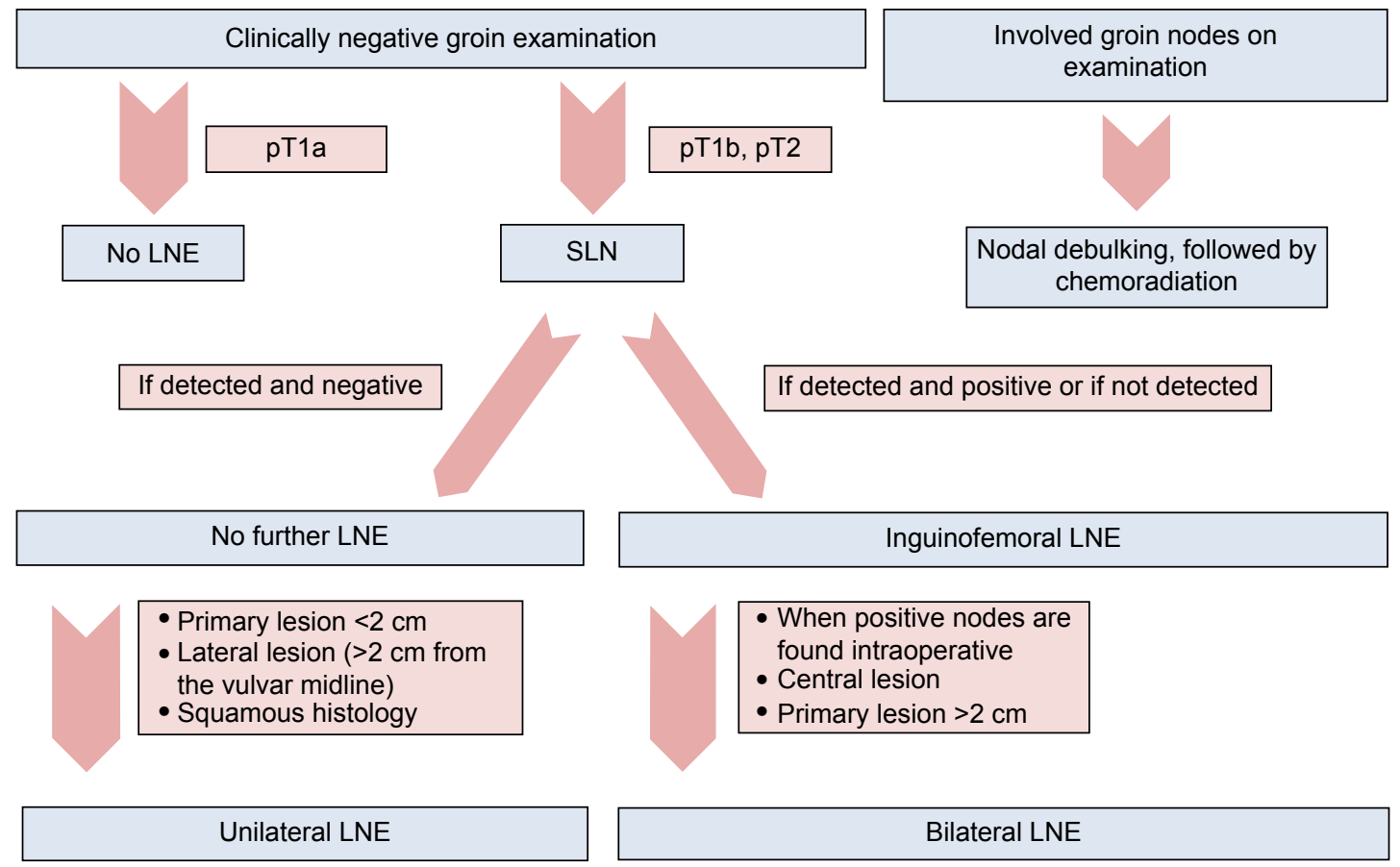

Figure 5 Standard of LNE in patients with vulvar cancer.

Abbreviations: LNE, lymphonodectomy; SLN, sentinel lymph node.

gamma detection device is used to identify the sentinel lymph node(s). ${ }^{47,48}$ It is estimated that only $25 \%-30 \%$ of patients with early stage vulvar cancer have lymph node metastases. ${ }^{42}$ If the sentinel node is positive, a full inguinofemoral lymphadenectomy followed by postoperative radiation therapy is recommended. If the sentinel lymph nodes identified by mapping are histologically negative, no further treatment is indicated. ${ }^{49}$ Even though lymphatic mapping and sentinel node biopsy are accurate for inguinal node staging, possible false negative results are taken into account for midline tumors. Unfortunately, midline tumors still pose the most difficult therapeutic decision. ${ }^{50}$

In principle, the idea of sentinel lymphadenectomy seems to be attractive also for vulvar cancer on account of the highly relevant postoperative morbidity of a systematic inguinofemoral lymphadenectomy. Unfortunately, however, groin recurrences after sentinel lymphadenectomy alone have been reported in various publications..$^{42,51-53}$ Even though, the sentinel procedure is performed only in the early tumor stage, morbidity with a $2.3 \%$ rate of groin recurrence has been shown by van der Zee et al. ${ }^{43}$ Since in the meantime prospective data on this topic have become available, sentinel lymphadenectomy can be considered an alternative to systematic bilateral inguinofemoral lymphadenectomy in cases of vulvar cancer when the patients are informed adequately. ${ }^{54}$

\section{Treatment approach}

Depending on the results of surgical staging, women are categorized as having early or advanced stage disease:

1) Early stage disease is defined as stage I or II. These patients should undergo a surgical excision including adjuvant treatment based on the findings at the time of surgery.

2) Locally advanced stage disease is defined as stage III or IVA. Operative treatment is preferred whenever feasible. Patients who are not surgical candidates should receive primary chemoradiation.

3) Stage IVB disease includes women with distant metastases - a primary chemotherapy is recommended, provided patients are candidates for systemic treatment. If not, palliative care is appropriate.

\section{Radiation}

\section{Primary radiochemotherapy}

For patients who are candidates for chemotherapy, chemoradiation might be preferred, according to the data for cervical cancer. ${ }^{55}$ In cases of anorectal, urethral, or bladder involvement, tumor that is fixed to the bone or gross lymph node involvement, chemoradiation is recommended. Cisplatin mono, 5-FU, or also mitomycin $\mathrm{C}$ in combination with radiation therapy should be performed. In some cases, surgery is possible after chemotherapy and radiation because of reduced tumor mass. ${ }^{56}$ 


\section{Chemotherapy and new biological agents}

Except for the neoadjuvant setting, chemotherapy for vulvar carcinoma is palliative and often ineffective $;{ }^{57}$ however, the most frequently used chemotherapy regimens are platinumbased, meaning they consist of cisplatin, given alone or in combination with another agent, such as 5-Fluouracil, paclitaxel, vinorelbine, or mitomycin C. ${ }^{58,59}$ Because of the small number of cases becoming necessary for a chemotherapy, there is no standard treatment yet. The actual response rate to these chemotherapies is low. Therefore, it is important to focus on new biological agents, such as gefitinib and erlotinib, which seem to have good results: gefitinib (Iressa) and erlotinib (Tarceva) are oral, reversible tyrosine kinase inhibitors. These enzymes are associated with the human Epidermal Growth Factor Receptor (EGFR). ${ }^{60}$ By inhibiting the tyrosine kinase, gefitinib and erlotinib prevent EGFRs from stimulating the uncontrolled growth of cells that contributes to tumor growth. Gefitinib combined with trastuzumab has been investigated in a human vulvar carcinoma cell line (A431) and seems to increase radiosensitivity. ${ }^{61}$

\section{Neoadjuvant radiation}

Even though fewer data are available, patients who are unable to undergo an operative treatment should receive primary radiation therapy (RT). The total dose of radiation should be between $60 \mathrm{~Gy}$ and $70 \mathrm{~Gy}$, and both the inguinal and the pelvic regions bilaterally should be treated if there is positive nodal involvement. ${ }^{62}$ In addition, RT can be used in the preoperative setting for women who present with advanced vulvar cancer. High rates of tumor shrinkage and complete responses at the time of surgery have been reported.

\section{Adjuvant radiation}

Radiotherapy of the inguinal and pelvic lymph drainage pathways or a pelvic lymphadenectomy in combination with an inguinal radiotherapy are recommended in cases with 3 or more afflicted lymph nodes together with macrometastases $>10 \mathrm{~mm}$ and a capsule rupture - this proceeding was the gold standard for a long time. ${ }^{63}$ Since the ASCO 2012, the indication for adjuvant radiation of the lymph drainage pathways has been enlarged: radiotherapy is already being discussed for patients with just one afflicted inguinal lymph node, as well as for $\mathrm{R} 1$ resection or marginal $\mathrm{R} 0$ resection without further surgical options. ${ }^{64}$

A variety of radiation techniques can be selected depending on the patient's conformation and scope of disease. Treatments should always be based on three-dimensional
Table 2 Survival by FIGO stage for patients with vulvar cancer 1999-200।, FIGO statistics

\begin{tabular}{lllll}
\hline FIGO stage & Number of patients & \multicolumn{3}{c}{ Overall survival } \\
\cline { 3 - 5 } & & I year & 2 years & $\mathbf{5}$ years \\
\hline I & 286 & 96.4 & 90.4 & 78.5 \\
II & 266 & 87.6 & 73.2 & 58.8 \\
III & 216 & 74.7 & 53.8 & 43.2 \\
IV & 7I & 35.3 & 16.9 & 13.0 \\
\hline
\end{tabular}

Note: Modified from International Journal of Gynecology \& Obstetrics; 95 Suppl I; Beller U, Quinn MA, Benedet JL, et al. Carcinoma of the Vulva. S7-27. Copyright ( 2006, with permission from Elsevier. ${ }^{69}$

Abbreviation: FIGO, International Federation of Gynecology and Obstetrics.

planning using high-quality CT or MRI images. Combined photon and electron techniques are often used to treat the regional nodes. In recent years, some clinicians have begun to use intensity-modulated radiation therapy (IMRT) or other inverse-planned, computer-controlled delivery techniques, which use computer-generated 3-D images to show the size and shape of the tumor and reduce radiation effects in collateral skin and soft tissue in the same way.

\section{Prognosis}

The prognosis of patients with vulvar cancer is quite good when convenient treatment is provided in a timely manner. Inguinal and/or femoral node involvement is the most significant prognostic factor for survival in patients with vulvar cancer. ${ }^{24,25}$ Extracapsular growth of lymph node metastases, two or more affected lymph nodes, and more than $50 \%$ replacement of lymph nodes by tumor are predictors of poor survival. The overall 5-year survival rate ranges from $70 \%$ to $93 \%$ for patients with negative nodes and from $25 \%$ to $41 \%$ for those with positive nodes. ${ }^{65}$ Other prognostic factors include stage, capillary lymphatic space invasion, and older age. ${ }^{32,66}$ Table 2 shows the survival rates depending on the FIGO stage. Recurrent lesions in the lymph nodes, as well as in distant sites, are not amenable to surgery or radiotherapy. They are difficult to treat, and the 5 -year survival rate is generally less than $5 \%{ }^{67}$

\section{Disclosure}

The authors report no conflicts of interest in this work.

\section{References}

1. Siegel R, Naishadham D, Jemal A. Cancer statistics, 2013. CA Cancer J Clin. 2013;63(1):11-30.

2. Hunter DJ. Carcinoma of the vulva: a review of 361 patients. Gynecol Oncol. 1975;3(2):117-123.

3. Gunther V, Alkatout I, Lez C, et al. Malignant melanoma of the urethra: a rare histologic subdivision of vulvar cancer with a poor prognosis. Case Rep Obstet Gynecol. 2012;2012:385175.

4. Way S. The anatomy of the lymphatic drainage of the vulva and its influence on the radical operation for carcinoma. Ann R Coll Surg Engl. 1948;3(4):187-209. 
5. Horn LC, Klostermann K, Hautmann S, Höhn AK, Beckmann MW, Mehlhorn G. HPV-assoziierte Veränderungen an Vulva und Vagina [HPV-associated alterations of the vulva and vagina. Morphology and molecular pathology]. Pathologe. 2011;32(6):467-475. German.

6. Ngan HY, Tsao SW, Liu SS, Stanley M. Abnormal expression and mutation of $\mathrm{p} 53$ in cervical cancer-a study at protein, RNA and DNA levels. Genitourin Med. 1997;73(1):54-58.

7. Jones RW, Baranyai J, Stables S. Trends in squamous cell carcinoma of the vulva: the influence of vulvar intraepithelial neoplasia. Obstet Gynecol. 1997;90(3):448-452.

8. Creasman WT, Phillips JL, Menck HR. The National Cancer Data Base report on early stage invasive vulvar carcinoma. The American College of Surgeons Commission on Cancer and the American Cancer Society. Cancer. 1997;80(3):505-513.

9. Landis SH, Murray T, Bolden S, Wingo PA. Cancer statistics, 1998. CA Cancer J Clin. 1998;48(1):6-29.

10. Crum CP. Carcinoma of the vulva: epidemiology and pathogenesis. Obstet Gynecol. 1992;79(3):448-454.

11. Sugiyama VE, Chan JK, Shin JY, Berek JS, Osann K, Kapp DS. Vulvar melanoma: a multivariable analysis of 644 patients. Obstet Gynecol. 2007;110(2 Pt 1):296-301.

12. Scurry J. Does lichen sclerosus play a central role in the pathogenesis of human papillomavirus negative vulvar squamous cell carcinoma? The itch-scratch-lichen sclerosus hypothesis. Int J Gynecol Cancer. 1999;9(2):89-97.

13. Jach R, Dyduch G, Radon-Pokracka M, et al. Expression of vascular endothelial growth factors VEGF- C and D, VEGFR-3, and comparison of lymphatic vessels density labeled with D2-40 antibodies as a prognostic factors in vulvar intraepithelial neoplasia (VIN) and invasive vulvar cancer. Neuro Endocrinol Lett. 2013;32(4):530-539.

14. Madeleine MM, Daling JR, Carter JJ, et al. Cofactors with human papillomavirus in a population-based study of vulvar cancer. $J$ Natl Cancer Inst. 1997;89(20):1516-1523.

15. Sideri M, Jones RW, Wilkinson EJ, et al. Squamous vulvar intraepithelial neoplasia: 2004 modified terminology, ISSVD Vulvar Oncology Subcommittee. J Reprod Med. 2005;50(11):807-810.

16. Medeiros F. Nascimento AF, Crum CP. Early vulvar squamous neoplasia: advances in classification, diagnosis, and differential diagnosis. Adv Anat Pathol. 2005;12(1):20-26.

17. Maclean AB. Vulval cancer: prevention and screening. Best Pract Res Clin Obstet Gynaecol. 2006;20(2):379-395.

18. van de Nieuwenhof HP, Massuger LF, van der Avoort IA, et al. Vulvar squamous cell carcinoma development after diagnosis of VIN increases with age. Eur J Cancer. 2009;45(5):851-856.

19. Trimble EL, Lewis JL Jr, Williams LL, et al. Management of vulvar melanoma. Gynecol Oncol. 1992;45(3):254-258.

20. Copeland LJ, Sneige N, Gershenson DM, McGuffee VB, AbdulKarim F, Rutledge FN. Bartholin gland carcinoma. Obstet Gynecol. 1986;67(6):794-801.

21. Fanning J, Lambert HC, Hale TM, Morris PC, Schuerch C. Paget's disease of the vulva: prevalence of associated vulvar adenocarcinoma, invasive Paget's disease, and recurrence after surgical excision. $\mathrm{Am} J$ Obstet Gynecol. 1999;180(1 Pt 1):24-27.

22. Pecorelli S. Revised FIGO staging for carcinoma of the vulva, cervix, and endometrium. Int J Gynaecol Obstet. 2009;105(2):103-104.

23. Al-Najar A, Alkatout I, Al-Sanabani S, et al. External validation of the proposed $\mathrm{T}$ and $\mathrm{N}$ categories of squamous cell carcinoma of the penis. Int J Urol. 2011;18(4):312-316.

24. Maggino T, Landoni F, Sartori E, et al. Patterns of recurrence in patients with squamous cell carcinoma of the vulva. A multicenter CTF Study. Cancer. 2000;89(1):116-122.

25. Burger MP, Hollema H, Emanuels AG, Krans M, Pras E, Bouma J. The importance of the groin node status for the survival of T1 and T2 vulval carcinoma patients. Gynecol Oncol. 1995;57(3):327-334.

26. Alkatout I, Naumann CM, Hedderich J, et al. Squamous cell carcinoma of the penis: predicting nodal metastases by histologic grade, pattern of invasion and clinical examination. Urol Oncol. 2010;29(6):774-781.
27. Sohaib SA, Richards PS, Ind T, et al. MR imaging of carcinoma of the vulva. AJR Am J Roentgenol. 2002;178(2):373-377.

28. Gunther V, Malchow B, Schubert M, et al. Impact of radical operative treatment on the quality of life in women with vulvar cancer-a retrospective study. Eur J Surg Oncol. 2014;40(7):875-882.

29. Hacker NF, Leuchter RS, Berek JS, Castaldo TW, Lagasse LD. Radical vulvectomy and bilateral inguinal lymphadenectomy through separate groin incisions. Obstet Gynecol. 1981;58(5):574-579.

30. Tantipalakorn C, Robertson G, Marsden DE, Gebski V, Hacker NF. Outcome and patterns of recurrence for International Federation of Gynecology and Obstetrics (FIGO) stages I and II squamous cell vulvar cancer. Obstet Gynecol. 2009;113(4):895-901.

31. Heaps JM, Fu YS, Montz FJ, Hacker NF, Berek JS. Surgical-pathologic variables predictive of local recurrence in squamous cell carcinoma of the vulva. Gynecol Oncol. 1990;38(3):309-314.

32. De Hullu JA, Hollema H, Lolkema S, et al. Vulvar carcinoma. The price of less radical surgery. Cancer. 2002;95(11):2331-2338.

33. Gonzalez Bosquet J, Magrina JF, Magtibay PM, et al. Patterns of inguinal groin metastases in squamous cell carcinoma of the vulva. Gynecol Oncol. 2007;105(3):742-746.

34. Rouzier R, Haddad B, Dubernard G, Dubois P, Paniel BJ. Inguinofemoral dissection for carcinoma of the vulva: effect of modifications of extent and technique on morbidity and survival. J Am Coll Surg. 2003;196(3):442-450.

35. Weikel W, Hoffman M, Steiner E, Knapstein PG, Koelbl H. Reconstructive surgery following resection of primary vulvar cancers. Gynecol Oncol. 2005;99(1):92-100.

36. Landoni F, Proserpio M, Manoe A, Cormio G, Zanetta G, Milani R. Repair of the perineal defect after radical vulvar surgery: direct closure versus skin flaps reconstruction. A retrospective comparative study. Aust N Z J Obstet Gynaecol. 1995;35(3):300-304.

37. Stehman FB, Bundy BN, Dvoretsky PM, Creasman WT. Early stage I carcinoma of the vulva treated with ipsilateral superficial inguinal lymphadenectomy and modified radical hemivulvectomy: a prospective study of the Gynecologic Oncology Group. Obstet Gynecol. 1992;79(4):490-497.

38. Klemm P, Marnitz S, Köhler C, Braig U, Schneider A. Clinical implication of laparoscopic pelvic lymphadenectomy in patients with vulvar cancer and positive groin nodes. Gynecol Oncol. 2005; 99(1):101-105.

39. Homesley HD, Bundy BN, Sedlis A, et al. Assessment of current International Federation of Gynecology and Obstetrics staging of vulvar carcinoma relative to prognostic factors for survival (a Gynecologic Oncology Group study). Am J Obstet Gynecol. 1991;164(4):997-1003; discussion 1003-1004.

40. Coleman RL, Ali S, Levenback CF, et al. Is bilateral lymphadenectomy for midline squamous carcinoma of the vulva always necessary? An analysis from Gynecologic Oncology Group (GOG) 173. Gynecol Oncol. 2013;128(2):155-159.

41. Iversen T, Aas M. Lymph drainage from the vulva. Gynecol Oncol. 1983;16(2):179-189.

42. de Hullu JA, Hollema H, Piers DA, et al. Sentinel lymph node procedure is highly accurate in squamous cell carcinoma of the vulva. J Clin Oncol. 2000;18(15):2811-2816.

43. Van der Zee AG, Oonk MH, de Hullu AJ, et al. Sentinel node dissection is safe in the treatment of early-stage vulvar cancer. J Clin Oncol. 2008;26(6):884-889.

44. Kim T, Giuliano AE, Lyman GH. Lymphatic mapping and sentinel lymph node biopsy in early-stage breast carcinoma: a metaanalysis. Cancer. 2006;106(1):4-16.

45. Mansel RE, Fallowfield L, Kissin M, et al. Randomized multicenter trial of sentinel node biopsy versus standard axillary treatment in operable breast cancer: the ALMANAC trial. J Natl Cancer Inst. 2006; 98(9):599-609.

46. Levenback CF, van der Zee AG, Rob L, et al. Sentinel lymph node biopsy in patients with gynecologic cancers Expert panel statement from the International Sentinel Node Society Meeting, February 21, 2008. Gynecol Oncol. 2009;114(2):151-156. 
47. Oonk MH, van de Nieuwenhof HP, van der Zee AG, de Hullu JA. Update on the sentinel lymph node procedure in vulvar cancer. Expert Rev Anticancer Ther. 2009;10(1):61-69.

48. Selman TJ, Luesley DM, Acheson N, Khan KS, Mann CH. A systematic review of the accuracy of diagnostic tests for inguinal lymph node status in vulvar cancer. Gynecol Oncol. 2005;99(1):206-214.

49. Oonk MH, van Hemel BM, Hollema H, et al. Size of sentinel-node metastasis and chances of non-sentinel-node involvement and survival in early stage vulvar cancer: results from GROINSS-V, a multicentre observational study. Lancet Oncol. 2010;11(7):646-652.

50. Hassanzade M, Attaran M, Treglia G, Yousefi Z, Sadeghi R. Lymphatic mapping and sentinel node biopsy in squamous cell carcinoma of the vulva: systematic review and meta-analysis of the literature. Gynecol Oncol. 2013;130(1):237-245.

51. Boran N, Kayikcioglu F, Kir M. Sentinel lymph node procedure in early vulvar cancer. Gynecol Oncol. 2003;90(2):492-493.

52. Fons G, ter Rahe B, Sloof G, de Hullu AJ, van der Velden J. Failure in the detection of the sentinel lymph node with a combined technique of radioactive tracer and blue dye in a patient with cancer of the vulva and a single positive lymph node. Gynecol Oncol. 2004;92(3):981-984.

53. Decesare SL, Fiorica JV, Roberts WS, et al. A pilot study utilizing intraoperative lymphoscintigraphy for identification of the sentinel lymph nodes in vulvar cancer. Gynecol Oncol. 1997;66(3):425-428.

54. Levenback CF, Ali S, Coleman RL, et al. Lymphatic mapping and sentinel lymph node biopsy in women with squamous cell carcinoma of the vulva: a gynecologic oncology group study. J Clin Oncol. 2012;30(31):3786-3791.

55. Shylasree TS, Bryant A, Howells RE. Chemoradiation for advanced primary vulval cancer. Cochrane Database Syst Rev. 2011;(4): CD003752.

56. Moore DH, Thomas GM, Montana GS, Saxer A, Gallup DG, Olt G. Preoperative chemoradiation for advanced vulvar cancer: a phase II study of the Gynecologic Oncology Group. Int J Radiat Oncol Biol Phys. 1998;42(1):79-85.

57. Martinez-Palones JM, Pérez-Benavente MA, Gil-Moreno A, et al. Comparison of recurrence after vulvectomy and lymphadenectomy with and without sentinel node biopsy in early stage vulvar cancer. Gynecol Oncol. 2006;103(3):865-870.
58. Tropé C, Johnsson JE, Larsson G, Simonsen E. Bleomycin alone or combined with mitomycin $\mathrm{C}$ in treatment of advanced or recurrent squamous cell carcinoma of the vulva. Cancer Treat Rep. 1980; 64(4-5):639-642.

59. Deppe G, Bruckner HW, Cohen CJ. Adriamycin treatment of advanced vulvar carcinoma. Obstet Gynecol. 1977;50(1 Suppl):13s-14s.

60. Henson ES, Gibson SB. Surviving cell death through epidermal growth factor (EGF) signal transduction pathways: implications for cancer therapy. Cell Signal. 2006;18(12):2089-2097.

61. Fukutome M, Maebayashi K, Nasu S, Seki K, Mitsuhashi N. Enhancement of radiosensitivity by dual inhibition of the HER family with ZD1839 ("Iressa") and trastuzumab ("Herceptin"). Int J Radiat Oncol Biol Phys. 2006;66(2):528-536.

62. Hacker NF, Berek JS, Juillard GJ, Lagasse LD. Preoperative radiation therapy for locally advanced vulvar cancer. Cancer. 1984; 54(10):2056-2061.

63. Homesley HD, Bundy BN, Sedlis A, Adcock L. Radiation therapy versus pelvic node resection for carcinoma of the vulva with positive groin nodes. Obstet Gynecol. 1986;68(6):733-740.

64. Barnes EA, Thomas G. Integrating radiation into the management of vulvar cancer. Semin Radiat Oncol. 2006;16(3):168-176.

65. Gadducci A, Cionini L, Romanini A, Fanucchi A,Genazzani AR. Old and new perspectives in the management of high-risk, locally advanced or recurrent, and metastatic vulvar cancer. Crit Rev Oncol Hematol. 2006;60(3):227-241.

66. Woolderink JM, de Bock GH, de Hullu JA, et al. Patterns and frequency of recurrences of squamous cell carcinoma of the vulva. Gynecol Oncol. 2006;103(1):293-299.

67. Lupi G, Raspagliesi F, Zucali R, et al. Combined preoperative chemoradiotherapy followed by radical surgery in locally advanced vulvar carcinoma. A pilot study. Cancer. 1996;77(8):1472-1478.

68. Schünke M, Schulte E, Schumacher U. Prometheus LernAtlas der Anatomie: Allgemenie Anatomie und Bewe gungssytem. [Prometheus learning Atlas of Anatomy: General Anatomy and Movement System]. 1st Ed. Thieme. Stuttgart, Germany; 2006. German.

69. Beller U, Quinn MA, Benedet JL, et al. Carcinoma of the Vulva. Int J Gynaecol Obstet. 2006 Nov;95 Suppl 1:S7-27.
International Journal of Women's Health

\section{Publish your work in this journal}

The International Journal of Women's Health is an international, peerreviewed open-access journal publishing original research, reports, editorials, reviews and commentaries on all aspects of women's healthcare including gynecology, obstetrics, and breast cancer. The manuscript management system is completely online and includes

\section{Dovepress}

a very quick and fair peer-review system, which is all easy to use. Visit http://www.dovepress.com/testimonials.php to read real quotes from published authors. 